\title{
PAINFUL SUBACUTE THYROIDITIS TREATMENT APPROACH
}

DOI: 10.36740/WLek202108125

\author{
Inna 0. Forkert' ${ }^{1}$, Oksana K. Melekhovets' ${ }^{1}$, Dmytro 0. Kalynychenko², Yurii V. Melekhovets' ${ }^{1}$, Evgen L. Kovalenko² \\ 'SUMY STATE UNIVERSITY, SUMY, UKRAINE \\ 2SUMY LASER CLINIC, SUMY, UKRAINE
}

\begin{abstract}
The aim: The study was aimed to compare the efficiency of intrathyroid steroid injection to oral steroid intake in patients with subacute thyroiditis. Materials and methods: 32 patients with subacute thyroiditis with insufficient result from NSAIDs treatment were randomly divided into two groups. The $1^{\text {st }}$ group received two intrathyroid steroid injections, the $2^{\text {nd }}$ group received oral prednisone. The results of the treatment were evaluated via ultrasound and evaluation of ESR and CRP at 0, 2, 4, 8 and 16 weeks of treatment.

Results: Patients of the $1^{\text {st }}$ group showed much faster result at the ultrasound compared to the $2^{\text {nd }}$ group: mean decrease in hypoechogenity area $44,42 \%$ vs $16,35 \%$ at week 2 , $p<0,001 ; 93,29 \%$ vs $75,98 \%$ at week $4, p<0,001 ; 97,8 \%$ vs $95,24 \%$ at week $8, p=0,4 ;$ mean decrease in ESR $66,34 \%$ vs $51,92 \%$ at week $2, p=0,023 ; 84,43 \%$ vs $74,94 \%$ at week $4, p=0,023$; mean decrease in CRP $26,53 \%$ vs $20,77 \%$ at week $2, p=0,024,33,77 \%$ vs $29,98 \%$, at week $4, p=0,026$. No side effects were noted during the treatment of patients of the $1^{\text {st }}$ group.

Conclusions: Compared to oral steroid intake intrathyroid steroid injection is faster, safer and generally better tolerated by patients.
\end{abstract}

KEY WORDS: subacute thyroiditis, intrathyroid steroid injection, treatment of subacute thyroiditis, betamethasone

Wiad Lek. 2021;74(8):1921-1924

\section{INTRODUCTION}

Subacute thyroiditis (SAT) is a virus-induced disease. It affects 12 in 100000 people, women are 3 to 5 times more susceptible than men [1]. Though most cases of the disease are self-limited, there is a risk of recurrence. In addition, $22,8 \%$ [2] to $26,8 \%$ [3] of patients develop permanent hypothyroidism. The predictive factors for development of permanent hypothyroidism are high cumulative doses of glucocorticoids, female gender [3], antibody positive and post-partum SAT [4], treatment with ibuprofen alone [2].

There is a rising evidence of post-COVID-19 subacute thyroiditis, making its treatment a relevant topic for discussion [5-11].

The treatment of SAT according to American Thyroid Association Guidelines includes symptomatic usage of non-steroidal anti-inflammatory agents (NSAIDs) to reduce pain which is followed by administration of prednisone in case NSAIDs don 't reduce pain effectively. Beta-blockers are used to relieve the symptoms of thyrotoxicosis [12].

The current treatment regimens result in a high rate of recurrence (19,8\% [2]) and persistent hypothyroidism. This implies a need for optimization of current practice and a search for new treatment options.

\section{THE AIM}

The aim of the study was to compare effectiveness of intrathyroid steroid injection (ISI) versus oral steroid administration.

\section{MATERIALS AND METHODS}

Total of 149 patients with diagnosed SAT that underwent treatment at Sumy Laser Clinic in years 2019 - 202132 patients were included in the study. Diagnosis criteria were pain in thyroid gland, preceding viral respiratory infection, ESR $>30 \mathrm{~mm} /$ hour, C-reactive protein $>10 \mathrm{mg} / \mathrm{l}$, diffuse heterogeneity and focal hypoechoic regions with a decreased color flow Doppler on sonography. Inclusion criteria were age between 30 and 60 years, no sufficient result from NSAIDs treatment for at least 10 days, ESR $>30 \mathrm{~mm} /$ hour, normal TSH and free $\mathrm{T}_{4}$ levels. Exclusion criteria were any acute or chronic condition that would limit the ability of the patient to participate in the study, refusal to give informed consent, pregnancy, diabetes mellitus, lactation, simultaneous intake of phenobarbital, rifampicin, phenytoin, ephedrine, diuretics, cardiac glycosides, amphotericin B, anticoagulants, antiplatelet agents, and somatotropin.

Written consent has been obtained from each patient or subject after full explanation of the purpose and nature of all procedures used

Patients were randomly divided into two groups 16 patients each by the day of birth 1-12 and 13-31 respectively.

The $1^{\text {st }}$ group received a course of prednisone $20 \mathrm{mg}$ per day for 4 weeks.

The second group received two ISIs with an interval of 4 weeks: at baseline and at 2 weeks control admission.

Steroid used for the ISI was Depos (PIC Farmak, Kyiv, Ukraine). $1 \mathrm{ml}$ of the substance contains $2 \mathrm{mg}$ of betamethasone $(6,43 \mathrm{mg}$ of betamethasone dipropionate micronized and 2,63 mg of betamethasone sodium phosphate). It is a combination of fast-solvable 
Table I. Mean hypoechogenity and ESR changes in patients of both groups.

\begin{tabular}{|c|c|c|c|c|c|}
\hline & TW0, M (SD) & TW2, M (SD) & TW4, M (SD) & TW8, M (SD) & TW16, M (SD) \\
\hline \multicolumn{6}{|c|}{ Mean hypoechogenity arean, px } \\
\hline 1 st group, $n=16$ & $9991,9(4014,7)$ & $\begin{array}{l}5622,2 \\
(2896) \\
\end{array}$ & $\begin{array}{c}911,8 \\
(1324,7)\end{array}$ & $\begin{array}{c}220,1 \\
(880,3)\end{array}$ & $\begin{array}{c}0,00 \\
(0)\end{array}$ \\
\hline 2nd group, $n=16$ & $10661(4222,6)$ & $\begin{array}{c}9253,5 \\
(4222,9) \\
\end{array}$ & $\begin{array}{c}3034,3 \\
(3351,1)\end{array}$ & $\begin{array}{c}629,5 \\
(1528,4) \\
\end{array}$ & $\begin{array}{c}5712,3 \\
(2705,7)\end{array}$ \\
\hline \multicolumn{6}{|c|}{ Mean ESR, mm/hour } \\
\hline 1st group, $\mathrm{n}=16$ & $\begin{array}{c}41,88 \\
(10,09) \\
\end{array}$ & $\begin{array}{l}14,06 \\
(9,02) \\
\end{array}$ & $\begin{array}{c}5,81 \\
(3,95) \\
\end{array}$ & $\begin{array}{c}5,88 \\
(6,05) \\
\end{array}$ & $\begin{array}{c}4,50 \\
(2,31) \\
\end{array}$ \\
\hline 2nd group, $n=16$ & $\begin{array}{l}42,06 \\
(7,38)\end{array}$ & $\begin{array}{c}20,63 \\
(10,81)\end{array}$ & $\begin{array}{l}10,44 \\
(5,21)\end{array}$ & $\begin{array}{c}11,69 \\
(14,05) \\
\end{array}$ & $\begin{array}{c}10,94 \\
(13,49) \\
\end{array}$ \\
\hline \multicolumn{6}{|c|}{ Mean CRP, mg/l } \\
\hline 1st group, $\mathrm{n}=16$ & $\begin{array}{l}27,92 \\
(6,73)\end{array}$ & $\begin{array}{c}5,63 \\
(3,61) \\
\end{array}$ & $\begin{array}{c}2,33 \\
(1,58) \\
\end{array}$ & $\begin{array}{c}2,35 \\
(2,42) \\
\end{array}$ & $\begin{array}{c}1,8 \\
(0,92) \\
\end{array}$ \\
\hline 2nd group, $n=16$ & $\begin{array}{l}28,04 \\
(4,92)\end{array}$ & $\begin{array}{c}8,25 \\
(4,33)\end{array}$ & $\begin{array}{c}4,18 \\
(2,09)\end{array}$ & $\begin{array}{c}4,68 \\
(5,62)\end{array}$ & $\begin{array}{c}4,38 \\
(5,40)\end{array}$ \\
\hline
\end{tabular}
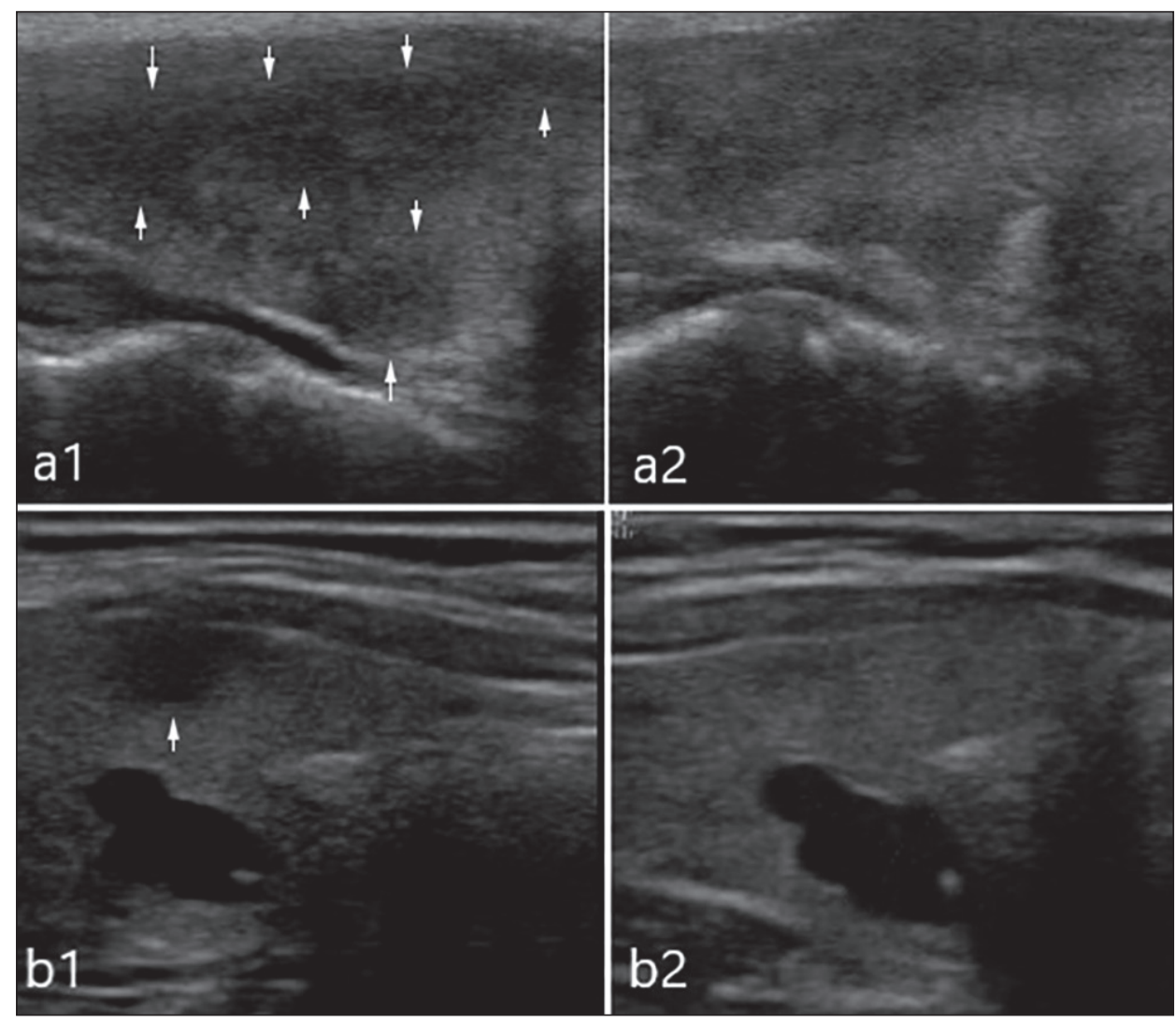

Fig. 1. a. 45-year-old woman from the 1st group with subacute thyroiditis. Longitudinal sonogram of heterogeneous right thyroid lobe: a1) hypoechoic areas (arrowheads) at baseline; a2) 2 weeks dynamics of hypoechoic areas.

b. 50-year-old woman from the 1st group with subacute thyroiditis and a thyroid cyst: b1) hypoechoic areas (arrow heads) at baseline; b2) 8 weeks dynamics. betamethasone sodium phosphate and slow-solvable micronized betamethasone dipropionate, which grants both a rapid (1 hour) and a postponed effect ( $>10$ days).

The procedure is held as follows: $1 \mathrm{ml}$ of the drug is pre-mixed with $2 \% 1 \mathrm{ml}$ lidocaine in a syringe with $12 \mathrm{~mm}$ needle; the front area of the neck is treated with chlorhexidine; the mixture of steroid and lidocaine is injected evenly into the thyroid (both lobes and the isthmus) supported by ultrasound guidance to avoid blood vessels. Distance between injections is approximately 10 $\mathrm{mm}$. After the procedure, the skin is again treated with chlorhexidine. The entire procedure lasts for 15 minutes, including ultrasound identification of the areas of interest and performing the injection.

The results of the therapy were ultrasound-controlled by a highly experienced sinologist with image review at the baseline admission, 2, 4, 8, and 16 weeks later.

Images of the thyroid ultrasound were saved and processed with ImageJ program. Hypoechogenity area was measured in pixels with ImageJ tool for area measurement on the images of transverse and longitudinal thyroid ultrasound. The probe for the images was placed on the patient's thyroid so that the maximum area of the hypoechogenity could be visualized. Salivary gland 
echogenity was used as a gauge for normal thyroid echogenity evaluation.

Laboratory analysis included ESR evaluation via Westergren method and CRP quantitative analysis on Behring Nephelometer.

Statistical analysis was held with Windows Excel data package, using Student's $t$ test. The data were approximately normally distributed and thus did not violate the assumptions of the $t$ test.

The study was approved by the Bioethics Commission of the Medical Institute of Sumy State University.

\section{RESULTS AND DISCUSSION}

\section{SONOGRAPHY FINDINGS}

At the baseline sonography (treatment week (TW) 0), all the patients had typical findings for the SAT: diffuse heterogeneity and focal hypoechoic regions that showed a decreased color flow Doppler. Surrounding tissue had a decreased color flow Doppler in 14 patients, 15 had an enhanced flow and 3 had normal one. Mean area of hypoechoic regions in the $1^{\text {st }}$ group was $9992 \mathrm{px}(95 \% \mathrm{CI}=7985$ to $11999 \mathrm{px})$ and $10661 \mathrm{px}$ (95\% CI 8550 to $12772 \mathrm{px}$ ) in the $2^{\text {nd }}$ group. Mean ESR of patients was $41,9 \mathrm{~mm} /$ hour $(95 \% \mathrm{CI}=36,8$ to $46,9 \mathrm{~mm} /$ hour$)$ in the $1^{\text {st }}$ group and $42,1 \mathrm{~mm} /$ hour $(95 \% \mathrm{CI}=38,4$ to $45,8 \mathrm{~mm} /$ hour) in the $2^{\text {nd }}$. Mean CRP of patients was $27,9 \mathrm{mg} / \mathrm{L}(95 \% \mathrm{CI}=24,6$ to $31,3 \mathrm{mg} / \mathrm{L})$ in the $1^{\text {st }}$ group and $28 \mathrm{mg} / \mathrm{L}(95 \% \mathrm{CI}=25,6$ to 30,5 $\mathrm{mg} / \mathrm{L}$ ) in the $2^{\text {nd }}$ (Table I).

At the second admission (TW 2), 16 patients of the $1^{\text {st }}$ group and 7 patients of the $2^{\text {nd }}$ group showed a decrease in sizes of hypoechoic region by more than $10 \%$ (Fig 1 ).

Patients of the $1^{\text {st }}$ group showed a significantly faster result: mean decrease in hypoechogenity area compared to TW 0 was $44,42 \%(95 \% \mathrm{CI}=37,59$ to $51,25 \%)$ in the $1^{\text {st }}$ group vs $16,35 \%$ $(95 \% \mathrm{CI}=7,33$ to $25,37 \%)$ in the $2^{\text {nd }}$ group $(\mathrm{p}<0,001)$. Mean ESR of patients in the $1^{\text {st }}$ group was significantly lower than of those in the $2^{\text {nd }}$ group: $14,1 \mathrm{~mm} /$ hour $(95 \% \mathrm{CI}=9,6$ to $18,6 \mathrm{~mm} /$ hour $)$ vs $20,6 \mathrm{~mm} /$ hour $(95 \% \mathrm{CI}=15,2$ to $26 \mathrm{~mm} /$ hour); $\mathrm{p}=0,024$. Mean CRP of patients in the $1^{\text {st }}$ group was as well significantly lower than of those in the $2^{\text {nd }}$ group: $5,6 \mathrm{mg} / \mathrm{L}(95 \% \mathrm{CI}=3,8$ to $7,4 \mathrm{mg} / \mathrm{L}$ ) vs $8,3 \mathrm{mg} / \mathrm{L}$ (95\% $\mathrm{CI}=6,1$ to $10,4 \mathrm{mg} / \mathrm{L}$ ); $\mathrm{p}=0,035$.

At the third admission (TW 4) among patients of the $1^{\text {st }}$ group, 10 had no signs of a lesion and 6 still had them, though hypoechogenity decreased in sizes. Mean decrease in hypoechogenity area was $93,29 \%$ in the $1^{\text {st }}$ group ( $95 \% \mathrm{CI}=88,38$ to $98,19 \%$ ) vs $75,98 \%(95 \% \mathrm{CI}=61,84$ to $88,11 \%)$ in the $2^{\text {nd }}$; $\mathrm{p}<0,001$. Mean ESR of patients in the $1^{\text {st }}$ group was still significantly lower than of those in the $2^{\text {nd }}$ group: $5,8 \mathrm{~mm} /$ hour $(95 \% \mathrm{CI}=3,8$ to 7,8 $\mathrm{mm} /$ hour) vs $10,4 \mathrm{~mm} /$ hour ( $95 \% \mathrm{CI}=7,8$ to $13 \mathrm{~mm} /$ hour); $p=0,022$. At this point patients of the $1^{\text {st }}$ group underwent the second injection, while the patients of the $2^{\text {nd }}$ group had their steroids gradually discontinued by $2,5 \mathrm{mg} / \mathrm{week}$.

At TW 8 control admission, the patients of the $2^{\text {nd }}$ group showed the following results: 13 were clinically stable and 3 had signs relapse: thyroid ultrasound showed focal echogenity with decreased blood flow on Doppler. They also had elevated ESR $(35,41$ and $42 \mathrm{~mm} /$ hour $) .1$ patient in the $1^{\text {st }}$ group still showed a slightly painful thyroid with some residual focal hypoechogenity on ultrasound ( $($ rea $=3521 \mathrm{px})$ and elevated ESR $(28 \mathrm{~mm} /$ hour $)$.
He was administered ibuprofen $400 \mathrm{mg}$ twice daily for 5 days and pain didn 't relapse after discontinuation. All the other patients of both groups showed no signs of SAT on ultrasound (Figure 1), normal ESR and CRP. ESR was normal in all patients but one with a relapse in the $1^{\text {st }}$ group $(28 \mathrm{~mm} /$ hour $)$ and 3 patients in the 2nd group (35, 41 and $42 \mathrm{~mm} /$ hour).

At TW 16 patients of the second group with a relapse still showed high ESR levels: 37, 37 and $40 \mathrm{~mm} /$ hour and sonographic signs of SAT. All other patients showed a stable result with no signs of inflammation.

\section{SIDE EFFECTS}

None of the patients of the $1^{\text {st }}$ group developed steroid-related side effects compared to the $2^{\text {nd }}$ group: 6 patients had an increase in weight $>5 \%, 5$ developed glucose intolerance, 4 had hypertension and 2 women had irregular menses.

ISI has been a debated and poorly studied treatment option recently. First ISI was held in 1974 [13]. In 1986, a patient was treated for severe recurrent Hashimoto thyroiditis with multiple intrathyroid injections of triamcinolone. This study was remarkable for the histological finding that showed an improvement in histological picture even on the day following injection, which showed a reformation of follicular structure and a reduction in epithelial cells swelling [14]. ISI was proved to inhibit Th2 cells in Graves' disease [15], which may also play a role in SAT pathogenesis [16]. Five cases of painful Hashimoto thyroiditis were successfully treated with injection of triamcinolone [17, 18]. In 2009 study, which included 191 patients with Graves' disease, ISI proved to successfully prevent a relapse [19]. A comprehensive meta-analysis is being held with no results published yet [20].

The current research proves ISI to be safe and effective in treatment of SAT. Though most cases of SAT are well controlled with NSAIDs, there are still many patients requiring steroids. Not only steroids can cause side effects in the doses given to reduce inflammation, but they also don't guarantee fast stable effect without recurrence.

\section{CONCLUSIONS}

ISI showed a rapid local effect without systemic or local side effects. It showed definitely faster result compared to systemic steroids: at TW 2 mean decrease in hypoechogenity area of $44,42 \%(95 \% \mathrm{CI}=37,59$ to $51,25 \%)$ in the $1^{\text {st }}$ group vs $16,35 \%(95 \% \mathrm{CI}=7,33$ to $25,37 \%)$ in the $2^{\text {nd }}$ group $(\mathrm{p}<0,001)$. Mean ESR of patients in the $1^{\text {st }}$ group was significantly lower than of those in the $2^{\text {nd }}$ group: 14,1 $\mathrm{mm} /$ hour ( $95 \% \mathrm{CI}=9,6$ to $18,6 \mathrm{~mm} / \mathrm{hour}$ ) vs $20,6 \mathrm{~mm} /$ hour ( $95 \% \mathrm{CI}=15,2$ to $26 \mathrm{~mm} /$ hour); $\mathrm{p}=0,024$. Mean CRP of patients in the $1^{\text {st }}$ group was as well significantly lower than of those in the $2^{\text {nd }}$ group: $5,6 \mathrm{mg} / \mathrm{L}(95 \% \mathrm{CI}=3,8$ to 7,4 $\mathrm{mg} / \mathrm{L}$ ) vs $8,3 \mathrm{mg} / \mathrm{L}(95 \% \mathrm{CI}=6,1$ to $10,4 \mathrm{mg} / \mathrm{L}) ; \mathrm{p}=0,035$.

Still there is a need for evaluation of drug absorption ratio, as thyroid is a greatly vascularized tissue. However, even if there is a systemic effect of steroid, ISI still requires much lower dosage to influence thyroid gland and there is no evidence of steroid-related side effects. All possible local side effects can be easily avoided due to US-navigation. 
It is also suitable for uncompliant patients. The result can be monitored by ultrasound alone and most of the patients require only one injection to achieve complete curation.

\section{REFERENCES}

1. Moini J., Pereira K., Samsam M. Subacute Thyroiditis. In Epidemiology of Thyroid Disorders. 2020;7: 152.

2. Sencar M.E., Calapkulu M., Sakiz D. et al., An Evaluation of the Results of the Steroid and Non-steroidal Anti-inflammatory Drug Treatments in Subacute Thyroiditis in relation to Persistent Hypothyroidism and Recurrence. Scientific Reports. 2019; 9(1): 16899. doi:10.1038/s41598019-53475-w.

3. Görges J., Ulrich J., Keck C. et al. Long-term Outcome of Subacute Thyroiditis. Experimental Clinical Endocrinology and Diabetes. 2020;128(11): 703-708. doi: 10.1055/a-0998-8035.

4. Stagnaro-Green A., Schwartz A., Gismondi R. et al. High rate of persistent hypothyroidism in a large-scale prospective study of postpartum thyroiditis in southern Italy. Journal of Clinical Endocrinology and Metabolism. 2011;96(3): 652-657. doi: 10.1210/jc.2010-1980.

5. Mattar S.A.M., Koh S.J.Q., Rama Chandran S. et al. Subacute thyroiditis associated with COVID-19. BMJ case reports. 2020;13(8). doi: 10.1136/ bcr-2020-237336.

6. Brancatella A., Ricci D., Viola N. et al. Subacute Thyroiditis After SarsCOV-2 Infection. The Journal of clinical endocrinology and metabolism. 2020;105(7). doi: 10.1210/clinem/dgaa276.

7. Campos-Barrera E., Alvarez-Cisneros T., Davalos-Fuentes M. Subacute Thyroiditis Associated with COVID-19. Case reports in endocrinology. 2020; 8891539. doi: 10.1155/2020/8891539.

8. Brancatella A., Ricci D., Cappellani D. et al. Is Subacute Thyroiditis an Underestimated Manifestation of SARS-CoV-2 Infection? Insights From a Case Series. The Journal of clinical endocrinology and metabolism. 2020;105(10): 537. doi: 10.1210/dinem/dgaa537.

9. Ippolito S., Dentali F., Tanda M.L. SARS-CoV-2: a potential trigger for subacute thyroiditis? Insights from a case report. Journal of endocrinological investigation. 2020; 43(8). doi: 10.1007/s40618-02001312-7.

10. Chakraborty U., Ghosh S., Chandra A. et al. Subacute thyroiditis as a presenting manifestation of COVID-19: a report of an exceedingly rare clinical entity. BMJ case reports. 2020;13(12): e239953. doi: 10.1136/ bcr-2020-239953.

11. Mehmood M.A., Bapna M., Arshad M. A Case of Post-COVID-19 Subacute Thyroiditis. Cureus. 2020;12(12): e12301. doi: 10.7759/cureus. 12301.

12. Ross D.S., Burch H.B., Cooper D.S. et al.2016 American Thyroid Association Guidelines for Diagnosis and Management of Hyperthyroidism and Other Causes of Thyrotoxicosis. Thyroid. 2016;26(10): 1343-1421. doi: 10.1089/thy.2016.0229.

13. Nagata I., Aoki N., Wakisaka G. Treatment of thyroid diseases with intrathyroidal injection of glucocorticoid. Nihon Naibunpi Gakkai Zasshi. 1974;50(4): 774-787. doi: 10.1507/endocrine1927.50.4_774.

14. Ishihara T., Mori T., Waseda N. et al. Pathological characteristics of acute exacerbation of Hashimoto's thyroiditis - serial changes in a patient with repeated episodes. Endocrinologia Japonica. 1986;33(5): 701-712. doi: 10.1507/endocrj1954.33.701.

15. He K., Jiang P., Liu B.L.etal. Intrathyroid injection of dexamethasone inhibits Th2 cells in Graves' disease. Archives of endocrinology and metabolism. 2020;64(3):243-250. doi: 10.20945/2359-3997000000244.
16. Wang X.L., Lv H.Z., Gan H.Y. et al. Role of Treg in the immune pathogenesis of subacute thyroiditis. Basic \& Clinical Medicine. 2018;38: 218-223.

17. Paja M., Del Cura J.L. Successful treatment of painful Hashimoto's thyroiditis with intrathyroidal injection of glucocorticoid in two patients. Endocrinologia, diabetes y nutricion.2018;65(9): 546-547. doi: 10.1016/j.endinu.2018.07.002.

18. Peng C.C., Huai-En Chang R., Pennant M. et al. A Literature Review of Painful Hashimoto Thyroiditis: 70 Published Cases in the Past 70 Years. Journal of the Endocrine Society. 2019; 4(2): bvz008. doi: 10.1210/ jendso/bvz008.

19. Mao X.M., Li H.Q., Li Q. et al. Prevention of relapse of Graves' disease by treatment with an intrathyroid injection of dexamethasone. Journal of Clinical Endocrinology and Metabolism. 2009;94(12): 4984-4991. doi: 10.1210/jc.2009-1252.

20. Li J., Zhang J., Jiang L. et al. Efficacy and safety of ultrasoundguided intrathyroidal injection of glucocorticoids versus routine oral administration of glucocorticoids for subacute thyroiditis: Protocol of systematic review and meta-analysis. Medicine (Baltimore). 2019;98(52): e18564. https://doi.org/10.1097/md.0000000000018564.

21. Watt T., Cramon P., Hegedüs L. et al. The thyroid-related quality of life measure ThyPRO has good responsiveness and ability to detect relevant treatment effects. Journal of Clinical Endocrinology and Metabolism. 2014; 99(10): 3708-3717. https://doi.org/10.1210/jc.2014-1322.

22. Watt T., Hegedüs L., Groenvold M., Bjorner J. et al. Validity and reliability of the novel thyroid-specific quality of life questionnaire, ThyPRO. European Journal of Endocrinology. 2014; 162(1): 161-167. https://doi.org/10.1530/eje-09-0521.

\section{ORCID and contributionship:}

Inna O. Forkert: 0000-0003-2777-0307 B,C,D

Oksana K. Melekhovets: 0000-0001-9031-7009 A,E,F

Yurii V. Melekhovets: 0000-0002-3219-9021 ${ }^{B}$

Evgen L. Kovalenko: 0000-0003-0750-9945 ${ }^{B}$

Dmitro O. Kalynychenko: 0000-0003-2412-3315 ${ }^{B}$

\section{Conflict of interest:}

The Authors declare no conflict of interest.

\section{CORRESPONDING AUTHOR}

\section{Inna 0. Forkert}

Sumy State University

10 Lebedinska Str, app. 35, 40021 Sumy, Ukraine

tel: +380955364942

e-mail: i.forkert@med.sumdu.edu.ua

Received: 22.03 .2021

Accepted: 30.07 .2021

A - Work concept and design, B - Data collection and analysis, C - Responsibility for statistical analysis,

D-Writing the article, $\mathbf{E}$-Critical review, $\mathbf{F}-$ Final approval of the article 